\title{
TEACHING QUANTITATIVE TECHNIQUES IN TIMES OF CORONA. EVALUATION OF AN INNOVATIVE TEACHING PROJECT TAKING INTO ACCOUNT GENDER AND ABRUPT VIRTUALITY
}

\author{
L. Freude, M. Domínguez Amorós, M.C. Catone, N. Vergés Bosch \\ Universitat de Barcelona (SPAIN)
}

\begin{abstract}
Quantitative research techniques are an important part of any Undergraduate program of sociology and other social sciences. Previous research shows that there is a need to innovate in order to improve the students' fluidity with quantitative techniques. Also, research indicates a gender gap in this field. Empower students in the usage of quantitative techniques is important, also considering its growing importance in terms of employability.
\end{abstract}

This article analyses the effectiveness of an educational innovation project in a multivariate techniques subject in the third year of the Sociology degree at the University of Barcelona. The evaluated activity aims to shift the students' attention from a predominant technical and focused perspective on quantitative research techniques towards an integrated and more complex process of learning, corresponding to daily activities of graduates in sociology at the labour market. In addition, a gender perspective has been incorporated, introducing topics related to inequality around gender and sexuality.

The objective of this evaluation is to evaluate the implementation of a workshop in social research techniques (multivariate analysis) considering the impact of gender and the accidental change from face-to-face to virtuality in the context of COVID. The workshop consisted in two sessions, the first of them presential, the second one virtual: in the first one, the students had to form groups and to choose between different fictional cases engaged by city councils; for the next session they were asked to prepare a first review of the literature, to elaborate a first diagnosis according to the fictional contract, and to review and pre-select different data sets. In the second accidentally virtual session, they were aimed to develop a model of multivariant analysis in order to respond to the fictional order.

Methodologically we based ourselves on two self-evaluations by the participants recollected through an online survey in the end of the class: a first one for the first face-to-face session and a second one for the virtual session. Students mainly assess their previous and subsequent knowledge. By bivariable and multivariable analysis we are going to check:

- If students improved their competences.

- What has been the effect of the confinement on their acquisition of competences.

- If there is a gender gap and if we mitigated the gender gap.

- If the topics chosen by the students show a Gender bias.

In terms of results we see that male students generally score higher in competences both, before and after the activity. That means that there is a gap and that the gap remains after the activity. There is a difference between the presential and the virtual activity though: in the virtually realized exercise female students improve more than boys; that means that here the gender gap is not dissolved but attenuated. We also noticed that women were more interested on topics on gender.

In conclusion can be said, that the activity itself was unable to dissolve the gender gap in quantitative research technique courses in Sociology, but that offering gender sensible topics is appreciated by female students. Also, we have seen that virtuality has helped to improve women's self-perceived competences.

Keywords: Techniques of Social Research, Sociology, Gender, Covid, Virtuality.

\section{INTRODUCTION}

On the following pages we are going to analyse an innovative teaching experience in a quantitative techniques class of a Sociology degree. First, we present where are we at in the debate on teaching quantitative techniques in Social Science. Considering that our experience was shaped importantly by 
distance teaching due to the lockout in Spain, we also introduce what has been said on E-Learning, blended Learning and distance teaching. Finally, we introduce some considerations on gender considering both before-mentioned aspects.

\subsection{On teaching quantitative techniques in Social Science}

Quantitative Social Research Techniques imply the domination of both, operational or technical elements as well as concrete and substantive research ([1]; [2]). Consequently, Quantitative Social Research Techniques are crucial for sociology students, both for comprehension and analysis of the social reality as well as their future employability ([3]). Therefor subjects on Quantitative Social Research Techniques constitute an important part of almost any sociological undergraduate program ([4]; [5]).

However, subjects on quantitative social research do not tend to be students' favourites ([6]). Computer, math and statistic anxiety have been discussed widely as one of its underlying reasons ([7]; [8]; [9]; [10], 2007; DeCesare, 2006). Also, research argues that students ignored that an important part of Sociology is based on numbers ([1]; [4]; [5]); the same authors argue that the technical terminology of methods is not easy to apprehend ([1]; [4]; [5]). Finally, students attending technique courses struggle with the three interrelating levels of methodology ([2]) - epistemology, methods and techniques - which need to be considered additionally to the substantive content ([4]; [5]); this supposes a complex learning situation.

Research on teaching quantitative techniques in social science makes various proposals in order to minimize the difficulties listed a above, for example: teaching techniques practically and not isolated, working with a wide range of examples appealing to a heterogeneous public and its context, introducing group work and formats which facilitate to talk about methods, and re-signifying the paper of the teacher in a sense of mentoring a practical and guided learning experience ([1]; [4]; [5]; [8]; [9]).

\subsection{On E-Learning at University}

In the last two decades - parallel to the digitalization - E-Learning and blended learning have been growing in the academic context, also in Sociology and Quantitative Techniques ([4]; [11]; [10]). Today a combined use of presential teaching and online platforms such as Moodles are common sense in almost any important University. Research on E-Learning and blended teaching has underlined its virtues, without denying its risks. Web based instructions and E-Learning are celebrated adapting to the students' needs being fundamentally asynchrony; by this, methods adapt to students' needs in time and space ([1]; [10]). Also, E-Learning and blended learning have been considered to boost another form of interaction, through ICT ([10]). Though E-Learning and blended learning have been celebrated generally, authors also comment possible risks: first, digital divides due to unequal access, ability or attitudes to computers; and second the lack of effective face-to-face interaction ([1]; [4]; [5]; [10]).

\subsection{On gender}

Feminist research made of gender a crucial variable in social science and feminist pedagogy claims to introduce gender in content and evaluation of teaching ([7]; [9]; [12]; [13]). Research on teaching of quantitative techniques showed that female students tend to underestimate their skills, overestimate the difficulties of the techniques as well as develop higher levels on statistic anxiety ([7]). While feminist methodologies are often critical with quantitative techniques - denouncing positivism, androcentrism or reification of binarism ([14]; [15]; Biglia \& Vergés, 2006), researchers on teaching quantitative methods make a claim for the inclusion of gender sensible content in method curses ([7]; [9]). Feminism especially cyberfeminist voices - strongly support E-Learning in the academic context, underlying its possibilities to adapt to women's life and undo gender avoiding face-to-face contact, always advocating for the inclusion of gender related content ([16]; [17]; [18]; [19]; [20]).

\subsection{Design of the activity}

The activity which we are going to describe in the following lines being the subject of our evaluation has been developed in the academic course 2019/20 in the Sociology Bachelor of the University of Barcelona, englobing more than 500 students in a four-year (240 ECT) training. Specifically, the activity has been implemented in a compulsorily subject on multivariant techniques in the second semester of the third year of the degree. The subject constitutes the third and last compulsory subject on quantitative methods equivalating 6 ECT. Over the semester we should have had two hours of theoretic class and two hours of practical class each week introducing mainly explorative loglinear models, factor analysis and cluster analysis. We counted with 139 matriculated students; 109 chose the continuous evaluation 
of which the here evaluated activity forms part, constituting a $10 \%$ of the final grade. In the sociology degree students can choose between two schedules, morning and evening, therefore we had two more or less fixed groups applying the same activity.

Table 1. Composition of groups

$\begin{array}{lrrr} & \text { Students } & \text { \% Students } & \text { Number of Groups } \\ \text { Social Groups / Inequality } & 17 & 17,3 & 4 \\ \text { Sports } & 6 & 6,1 & 1 \\ \text { Politics, Participation and Youth } & 28 & 28,6 & 3 \\ \text { Exclusion of LGTB } & 25 & 25,5 & 5 \\ \text { (Re-)productive work and gender } & 20 & 20,4 & 4\end{array}$

We designed a Problem Based Learning Seminar ([21]) in order to tackle with the challenges of teaching quantitative method courses above-mentioned. In a first practical class in the second week of the course, we explained that the aim of this seminar was that they worked in groups on given practical cases putting into practice what they have learnt at class. We emphasized that we wanted them to discuss and explore collectively linking content and technique, making them reflex and argue on the use of techniques. Also, we presented a calendarization of tasks and three group sessions over the whole course. Afterwards we presented five different topics imitating concourses of public administrations for consultancy firms on sociodemographic groups and inequality (1), sports (2), exclusion of lesbians, gays, trans ${ }^{*}$ and bisexuals (3), politics, participation and youth (4) and (re-)productive work and gender (5). The students formed groups autonomously and the result can be observed in table 1.

Once the groups were formed, they started the first activity which was aimed to deepen in the theoretical background of their topic, design objectives for their project, research questions and/hypothesis. Also, we asked them to identify sources of information as well as possible datasets. All groups had the task to present their results in a short report, to be handed in till the next session.

The second session we would discuss their proposals; afterwards the students would continue to select sources of information and datasets, weighting up its advantages and disadvantages; they were also asked to make a preliminary proposal for the design of analysis, that is which variables and techniques to use in order to achieve their objectives.

In a third session, already at the end of the course, students would have presented their empirical results and would have interrogated each other, to what extend they were able to contrast their hypothesis and/or answer their research questions, what were the main difficulties they found, etc.

Due to restrictions which supposed the closure of University buildings at the 13th of March 2020 till the end of the semester, we just did the first session presentially and agreed with the students to cancel the third session and its content, as we were mostly interested in the design of the analysis.

\section{METHODOLOGY}

In order to evaluate the activity, we initially wanted to check the three first ideas adding a fourth one considering the effect of the confinement:

- If students improved their competences.

- If there is a gender gap and if we mitigated the gender gap.

- If the topics chosen by the students show a Gender bias.

- If the confinement influenced the acquisition of competences.

Therefor we developed a questionnaire to be answered by our students after every session, indicating their initial knowledge before the class and their final knowledge after the class. We also asked for their satisfaction with group work and how they evaluated different aspects of studying confined at home.

\subsection{Questionnaire first class}

At the very beginning of the questionnaire to be filled out after class, we asked our students to answer on a scale from one to ten their initial knowledge on the topic they are working on (1), the formulation of 
a research problem (2), the formulation of research objectives (3), the formulation of research hypothesis (4) and the research of datasets (5). At the end of the questionnaire they scored their final knowledge after the class on the same items.

They also positioned on a scale measuring their degree of agreement (do not agree at all; do not agree; agree; agree a lot) on the following sentences: this class helped me to get aware of my difficulties (1), I already knew the sources of information used in this activity (2), during the class I had more direct dialogue with the teachers (3), after the activity, the theoretic classes treated till now are clearer to me (4) and after this class I am more curious to think about contemporary social phenomena (5).

On the same scale they scored their agreement on three ideas on group work: I would have preferred to do this activity alone (1), group work helped me to understand better how to develop a research (2) and group work required more effort than an individual task (3). They also indicated their perceived participation in group work as very little, little, strong or very strong.

\subsection{Questionnaire second class}

The second questionnaire also evaluated initial and final knowledge on a scale between one and ten considering sources on information (1), selection of datasets (2) and selection of techniques of analysis (3). Considering group work we measured the agreement (do not agree at all, do not agree, do agree, totally agree) on three items: I would have preferred to do this activity alone (1), Group work made the activity less boring (2) and group work permitted me to feel part of our class during this period of confinement (3). Also concerning the effects of the lockdown we ask for the degree of agreement (do not agree at all, do not agree, do agree, totally agree) on four ideas: participating in this activity virtually required more effort than presential at university (1), internet and the technological tools I dispose permitted me to do this activity without difficulty (2), internet and the technological tools I used permitted me to participate more actively than in a presential class (3) and working from home resulted more comfortable (4).

\subsection{Data and techniques}

As described above we counted with 109 participants in this activity. The first questionnaire has been responded by only 68 respondents ( 29 male, 38 female, 1 other); the second questionnaire has been responded by 98 respondents ( 42 male, 53 female, 3 other).

In the results we are going to present first univariant analysis and some bivariant analysis checking for gender differences considering just men and women.

\section{RESULTS}

\subsection{Knowledge before and after the activity}

In the first, presential activity we asked our students to evaluate their previous and posterior knowledge on five of the key-competences to be worked in the activity on a scale between one and ten: specific knowledge on the case, formulation of a research topic, formulation of research objectives, hypothesis and a preliminary research on databases. The means oscillate between six and 7,1, being the mean of the initial knowledge lower than the mean of the final evaluation. In concrete, the formulation of a research topic ,7647 improved the most, followed by formulation of research objectives, 7353 . Specific knowledge on the topic of the case grew ,6765 points and research of databases ,6324. The lowest increment has been reached in formulation of research hypothesis 4118 . It should be mentioned that we only reached 68 responses (62,39\% of the 109 participants), which means an elevated no-response.

In the second, activity realized confined at home, our students evaluated their previous and posterior knowledge on three different key-competences to be worked in the activity on a scale between one and ten: control over different sources of information, selection of databases and selection of the research techniques. The means are considerably lower than in the first case and oscillate between 4,9 and 6,6. The perceived improvement of our students, instead, is higher: in terms control over different sources of information the results are 1,0102 higher after the activity; for the selection of databases they improve , 8673 points and in the case of selection of techniques , 8163 points. In the second round $89,91 \%$ of the 109 students responded the questionnaire. 


\subsection{The effect of the confinement on their acquisition of competences}

It is difficult to compare the results of the two activities: firstly, because the first activity counted with less responses; secondly, because we do not know if the content of the two sessions had a significantly different level or complexity, or if the change of the learning setting from presential face-to-face to virtual made the difference. Considering the bare numbers, it seems to be that virtuality boosted the acquisition of competences.

\subsection{First activity: evaluation of the activity and group work}

Besides from competences we have seen that most $(63,2 \%)$ but not all the students agree that the activity helped to make them aware of their difficulties. They evaluate similarly the novelty of the content: again, more than a third part of the students already knew the sources of information introduced at class $(39,7 \%)$. For sure, the highest degree of agreement received the affirmation that during the activity they had a more direct dialog with the teachers $(79,4 \%)$. A slight majority of the students does not consider, that after the activity the topics were clearer $(51,5)$. For sure a preoccupying result. A very high score of agreement receives the idea that after the activity I have more curiosity in order to think critically about contemporary social phenomena $(77,9 \%)$. In this case, we also observed a gender sensible impact. Female students less often disagreed totally with this affirmation.

For most of the students, teamwork has been evaluated positively compared to individual activity $(80,9 \%)$. This item has been gender sensitive, female students overproportionaly agreeing totally and underproportionally agreeing a bit. Students also agreed that the activity helped them understand better how deal with a research problem $(79,4 \%)$. A considerable number of students $(39,7 \%)$ considered that the activity supposed more efforts than an individual activity. Almost all the students perceived their participation as strong or very strong (95.6\%).

\subsection{Second activity: group work and corona}

Again, now in period of lock-down, our students still preferred to do group work (78,6\%); and again, this item is gender sensitive: in this case male students do agree moderately overproportionally. In general, the majority affirm that group work was less boring $(72,4 \%)$ and permitted them to feel part of the class $(68,4 \%)$ despite of the isolation due to the lock down. At the same time, they also admit that the activity in the new circumstances required more efforts $(81,6 \%)$. Stands out that just a minority of the students believed that internet and the technical devices they dispose, permitted them to do the activity without difficulty (49\%); in this sense, not even a third of the class agrees that Internet and the technical devices used permitted them to participate more actively in the class $(22,4 \%)$. In the same vein, only $20,4 \%$ agrees that working from home resulted comfortable to them.

\subsection{Gender impact}

In the first activity we can observe that women's mean always indicate lower results than the men's mean, but these differences are not statistically different. In terms of improvement men also improve stronger, less in formulating hypothesis; anyway, the differences are not statistically significant. In the second activity happens the same.

Considering the gender sensibility of the proposed topics our data shows a global association between gender and topics chosen; this association is especially strong in the case of youth and politics - where we denote an exclusive preference of male students - and Gender and Work where much more women have been interested.

\section{CONCLUSIONS}

In conclusion it can be said that in this experience teaching quantitative techniques in a practical way relating them to substantial content and relying heavily on group work, students improved their knowledge on methods. Also, students appreciated strongly groupwork (even during the confinement) although they considered group work more laborious. They notice a more fluent and direct contact with the teacher.

Considering gender, we could not observe strong differences in terms of previous knowledge, posterior knowledge or acquired knowledge. We did observe differences in the selection of topics, which supports the idea to include gender related topics into classes on quantitative techniques. 
Concerning distance teaching, we observed a higher acquisition of knowledge - though we cannot attribute his only to distance teaching. On the other hand, students felt that would have performed better in a presential setting.

\section{ACKNOWLEDGEMENTS}

This paper has been elaborated with the support of the Marie Curie Alumni Association.

\section{REFERENCES}

[1] M. Catone and P Diana, "Social Research Methods 2.0: e-learning design", in Journal of eLearning and Knowledge Society, 13(3), 2017.

[2] P. López-Roldán, and S. Fachelli, Metodología de la investigación social cuantitativa. Universitat Autònoma de Barcelona, 2015.

[3] M. Domínguez Amorós and J.A. Gómez Yáñez, "Formación y competencias en la profesión del sociólogo/a", in Revista Española de Sociología, 2016, vol. 25, num. 3, pp. 17-43, 2016.

[4] P. Diana, and M.C. Catone, "Innovations in teaching social research methods at the University in the digital era: An Italian case study", in Italian Journal of Sociology of Education, 10(1), 128-165, 2018.

[5] P. Diana and M.C. Catone, "E-learning in an Undergraduate Course in Research Methods for the Social Sciences: Reflections on Teaching", in Italian Journal of Sociology of Education, 8(2), 2016.

[6] M. DeCesare, "'Statistics anxiety' among sociology majors: A first diagnosis and some treatment options", in Teaching Sociology, 35(4), pp. 360-367, 2016.

[7] T. Verge, "The Virtues of Engendering Quantitative Methods Courses", in PS, Political Science \& Politics, 49(3), p. 550, 2016.

[8] J. Adriaensen, B. Kerremans, and K. Slootmaeckers, "Editors' Introduction to the Thematic Issue: Mad about Methods? Teaching Research Methods in Political Science" in Journal of Political Science Education, 11, 1, pp. 1-10, 2015.

[9] K. Slootmaeckers, B. Kerremans and J. Adriaensen, "Too Afraid to Learn: Attitudes towards Statistics as a Barrier to Learning Statistics and to Acquiring Quantitative Skills", in Politics, 34(2), pp. 191-200, 2014.

[10] K. Van Gundy, B.A. Morton, H.Q. Liu, and J. Kline, "Effects of Web-Based Instruction on Math Anxiety, the Sense of Mastery, and Global Self-Esteem: A Quasi-Experimental Study of Undergraduate Statistics Students" in Teaching Sociology, 34(4), pp. 370-388, 2006.

[11] C.J. Auster, "Blended learning as a potentially winning combination of face-to-face and online learning: An exploratory study", in Teaching Sociology, 44(1), 39-48, 2016.

[12] B. Biglia and N. Vergés Bosch, "Cuestionando la perspectiva de género en la investigación" in REIRE. Revista d'Innovació i Recerca en Educació, 2016, vol. 9, num. 2, pp. 12-29, 2016.

[13] I. M. Martín, "Construcción de una pedagogía feminista para una ciudadanía transformadora y contra-hegemónica", in Foro de Educación, (20), pp. 129-151, 2016.

[14] A.C. Nowakowski, J.E. Sumerau and L.A. Mathers, "None of the above: Strategies for inclusive teaching with "representative" data", in Teaching Sociology, 44(2), pp. 96-105, 2016.

[15] N. Spierings, N. "The inclusion of quantitative techniques and diversity in the mainstream of feminist research." in European Journal of Women's Studies, 19(3), pp. 331-347, 2012.

[16] C. Herman, and G. Kirkup, "Combining feminist pedagogy and transactional distance to create gender-sensitive technology-enhanced learning", Gender and Education, 29(6), pp. 781-795, 2017.

[17] B. Biglia and Edurne, J. Los desafíos de la pedagogía cyberfeminista: un estudio de caso. Athenea Digital. Revista de pensamiento e investigación social, 12(3), 2012. 
[18] M. Luxán Serrano and B. Biglia, "Pedagogía cyberfeminísta: Entre utopía y realidades", in Teoría de la Educación. Educación y Cultura en la Sociedad de la Información, 12(2), 2011.

[19] B. Kossek, Empfehlungen für eine geschlechtersensible Didaktik des eLearning. Universität Wien - Projektzentrum Lehrentwicklung, 2006.

[20] B. Liebig, E. Rosenkranz-Fallegger and U. Meyerhofer, Gelebte Gender-Kompetenz Checklisten für Hochschulen und Dozierende. vdf Verlag, 2009.

[21] C. Vidal Figueroa, G. Castillo Rozas, and C. Castillo Rozas, "El Aprendizaje Basado en Problemas (ABP) en Ciencias Sociales: resultados de una experiencia en estudiantes de postgrado en Chile", in International Conference on Innovation, Documentation and Teaching Technologies, INNODOCT, 2018. 